\title{
TELETRABALHO: UMA REVISÃO INTEGRATIVA DA LITERATURA INTERNACIONAL
}

\author{
TELEWORKING: AN INTEGRATIVE REVIEW OF \\ INTERNATIONAL LITERATURE
}

\section{TELETRABAJO: UNA REVISIÓN INTEGRATIVA DE LA LITERATURA INTERNACIONAL}

\author{
Ana Luiza Leite \\ Mestranda em Administração na Universidade do \\ Estado de Santa Catarina, Brasil \\ anaetiel@yahoo.com.br \\ Dannyela da Cunha Lemos \\ Docente da Universidade do Estado de Santa \\ Catarina, Brasil \\ Doutora em Administração pela Universidade \\ Federal de Santa Catarina, Brasil \\ lemosda@gmail.com
}

\author{
Wilnei Aldir Schneider \\ Doutor em Administração pela Universidade do \\ Estado de Santa Catarina, Brasil, e pela Università \\ di Bologna, Itália \\ was.was@hotmail.com
}

\author{
Contextus \\ ISSNe 2178-9258 \\ Organização: Comitê Científico Interinstitucional \\ Editor-Chefe: Diego de Queiroz Machado \\ Avaliação: double blind review pelo SEER/OJS \\ Artigo indicado para fast-track no XXII Seminários em \\ Administração (SEMEAD 2019) \\ Recebido em 19/11/2019 \\ Aceito em 22/11/2019 \\ Versão final aceita em 01/12/2019 \\ http://dx.doi.org/10.19094/contextus.v17i3.42743
}

\begin{abstract}
RESUMO
Objetivou-se analisar a produção científica disponível em bases de dados internacionais sobre o teletrabalho, com o intuito de verificar o volume da produção e identificar o foco de estudo dos artigos, por meio da revisão integrativa. A produção científica é crescente, com grande quantidade de artigos de revisão (12). Em relação aos artigos empíricos, com abordagem predominantemente quantitativa, nota-se a baixa publicação em organização públicas. Estados Unidos e Reino Unido lideram o ranking de quantidade de publicações, assim como a lista dos artigos mais citados. O foco dos estudos está na busca de impactos causados pela implementação do teletrabalho ao trabalhador e à organização. Identifica-se que há poucos estudos de cunho longitudinal e poucos combinando os diversos atores envolvidos no teletrabalho, principalmente em relação às equipes de trabalho.
\end{abstract}

Palavras-chave: teletrabalho; teletrabalho; trabalho em casa; formas flexíveis de trabalho; revisão integrativa.

\begin{abstract}
The purpose was to analyze the scientific production available in international databases on telework in order to verify the volume of production and to identify the articles' focus of study through the integrative review. Scientific production is growing, with a large number of review articles (12). Regarding empirical articles, with a predominantly quantitative approach, there is a low rate of publication in public organizations. The United States and the United Kingdom top the ranking of publications, as well as the list of the most cited articles. The studies focus on the search for impacts caused by implementing telework for both the worker and the organization. There are few studies of longitudinal nature and few combining the various actors involved in telework, especially with respect to work teams.
\end{abstract}

Keywords: teleworking; telecommuting; home office; flexible work arrangements; integrative review.

\section{RESUMEN}

El objetivo fue analizar la producción científica disponible en bases de datos internacionales sobre teletrabajo, para verificar el volumen de producción e identificar el foco de estudio de los artículos, a través de la revisión integradora. La producción científica está creciendo, con una gran cantidad de artículos de revisión (12). En cuanto 
a los artículos empíricos, con un enfoque predominantemente cuantitativo, existe una baja publicación en las organizaciones públicas. Estados Unidos y el Reino Unido encabezan el ranking de publicaciones, así como la lista de los artículos más citados. El enfoque de los estudios está en la búsqueda de impactos causados por la implementación del teletrabajo al trabajador y la organización. Se identifica que existen pocos estudios de naturaleza longitudinal y pocos que combinen los diversos actores involucrados en el teletrabajo, especialmente en relación con los equipos de trabajo.

Palabras clave: teletrabajo; teletrabajo; trabajo en casa; formas flexibles de trabajo; revisión integradora.

\section{INTRODUÇÃO}

Um dos desafios da gestão de pessoas tem sido as modificações a ocorrer no tradicional modelo de trabalho das organizações. Nesse contexto, a flexibilidade de trabalho se amplia como uma realidade no mercado, tanto como parte da estratégia organizacional, quanto como promessa de desafios, autonomia e versatilidade para o colaborador (ADERALDO; ADERALDO; LIMA, 2017). A flexibilização do trabalho pode ser vista, também, como ferramenta inovadora na área de gestão de pessoas (HIDALGO; ALBORS, 2008).

Frolick, Wilkes e Urwiler (1993) já alertavam que as empresas que veem a flexibilidade de trabalho como uma alternativa a encontrar resultados em vantagem competitiva em relação a força de trabalho, vão trazer novos desafios aos gestores nos próximos anos. Afinal, com o desenvolvimento e a popularização das tecnologias de informação e comunicação (TIC), a possibilidade de poder trabalhar em qualquer lugar se tornou uma realidade bastante acessível e, muitas vezes, atrativa (ROCHA; AMADOR, 2018).

A flexibilização do trabalho refere-se à flexibilidade de horários, lugar e modo de realização do trabalho, entre outros aspectos. O teletrabalho é justamente uma forma de flexibilidade laboral, o qual tem sido utilizado como sinônimo de diversos outros termos: home office, trabalho remoto, trabalho a distância, trabalho em casa, telework, telecommuting, entre outros (VAN DEN BROEK; KEATING, 2011). Na presente pesquisa, utiliza-se o termo teletrabalho, que é entendido como um modo de exercer o trabalho fora da estrutura física da organização com utilização de tecnologias da informação e comunicação em tempo parcial ou integral. A falta de uma única definição do teletrabalho torna difícil a quantificação e qualificação do fenômeno. Quanto mais amplamente compartilhada a definição, mais fácil será estimar o número de teletrabalhadores em um país ou região específicos (TREMBLAY, 2002) e gerir essa nova forma de trabalho.

Atualmente, estimar a quantidade de teletrabalhadores no mundo se mostra uma tarefa difícil: os números disponíveis na literatura são consideravelmente divergentes, entretanto, é unânime a constatação da tendência de forte aceitação mundial dessa modalidade de trabalho, 
bem como seu acelerado crescimento (ROCHA; AMADOR, 2018). A prática do teletrabalho vem crescendo no Brasil, visto que de acordo com dados da Sociedade Brasileira de Teletrabalho e Teleatividades - SOBRATT (2014), em torno de doze milhões de pessoas no país já trabalham a distância. Contudo, mesmo com o número de teletrabalhadores em ascensão (TUNG; TURBAN, 1996; VARGAS; OSMA, 2013) desde o início da década de 1970, esse número tem se mantido abaixo das expectativas (VAN SELL; JACOBS, 1994; PÉREZ; SÁNCHEZ; CARNICER, 2002).

As formas flexíveis de trabalho constituem tema relativamente recente, tanto como prática quanto na literatura administrativa, especialmente no Brasil (DA COSTA, 2007). A partir das buscas realizadas por Da Silva (2014), foi possível perceber que este tema tem ganhado importância, uma vez que os anos de maior incidência de publicações foram 2012, 2010 e 2008. Percebe-se, também, que ainda há espaço para pesquisas que avançam na direção do impacto do teletrabalho dentro da empresa (DA SILVA, 2014). Bélanger, Watson-Manheim e Cisne (2013) notaram, ainda, que há poucos estudos que abordaram os efeitos do teletrabalho ao longo do tempo. Nesse sentido, buscou-se entender como o tema teletrabalho tem sido tratado na literatura internacional, em busca de alinhar novos estudos e expor lacunas teóricas ainda não exploradas.

Com o portifólio de artigos definidos, o objetivo geral deste estudo é analisar a produção científica disponível em bases de dados internacionais acerca do teletrabalho. Em termos específicos, busca-se: i) analisar o volume da produção científica acerca do teletrabalho; ii) identificar, a partir da literatura, os impactos do teletrabalho nas organizações; e iii) identificar o foco de estudo dos artigos.

\section{REFERENCIAL TEÓRICO}

Em sentido amplo, percebe-se que em diferentes conceituações de teletrabalho há a caracterização do local de trabalho, do tempo de trabalho (integral ou parcial) e do uso de tecnologias da informação e comunicação. O Quadro 1 apresenta conceituações de diferentes autores ao longo do tempo: 
Quadro 1 - Um olhar conceitual sobre teletrabalho

\begin{tabular}{|l|l|}
\hline Autores | Ano & Conceituação de Teletrabalho \\
\hline Nilles (1988) & $\begin{array}{l}\text { Teletrabalho é um termo cunhado pelo autor em 1973 para se referir à } \\
\text { substituição parcial ou total do trajeto duas vezes ao dia para o trabalho pelo } \\
\text { uso de telecomunicações e computadores. }\end{array}$ \\
\hline $\begin{array}{l}\text { Van Sell e } \\
\text { Jacobs (1994) }\end{array}$ & $\begin{array}{l}\text { É caracterizado pela utilização de computadores e equipamentos de } \\
\text { telecomunicações para trabalhar em casa ou em um local remoto, um ou } \\
\text { mais dias por semana. }\end{array}$ \\
\hline $\begin{array}{l}\text { Illegems } \\
\begin{array}{l}\text { Verbeke } \\
(2004)\end{array}\end{array}$ & $\begin{array}{l}\text { Definimos o teletrabalho como trabalho remunerado a partir de casa, de um } \\
\text { escritório satélite, de um centro de teletrabalho ou de qualquer outra estação } \\
\text { de trabalho fora do escritório principal por pelo menos um dia. }\end{array}$ \\
\hline $\begin{array}{l}\text { Rosenfield e } \\
\text { de } \\
(2011)\end{array}$ & $\begin{array}{l}\text { Elves sentido restritivo, teletrabalho pode ser definido como trabalho a } \\
\text { distância com utilização de TICs }\end{array}$ \\
\hline
\end{tabular}

Fonte: elaboração própria.

No que tange à localização do trabalho (HADDON; BRYNIN, 2005; NILLES, 1988; PÉREZ; SÁNCHEZ; CARNICER, 2002; TREMBLAY, 2002), verificam-se as seguintes distinções:

(a) Home office, home-based work ou homework (AGUILERA et al., 2016; HADDON; BRYNIN, 2005): é uma categoria específica dentro do contexto maior do telework ou telecommuting, que trata da peculiaridade de ser realizado na casa do trabalhador (ROCHA; AMADOR, 2018);

(b) Escritórios satélites: extensões atomizadas da empresa central (TREMBLAY, 2002; ROSENFIELD; DE ALVES, 2011);

(c) Telecentros: estabelecimentos próximos a moradia dos trabalhadores que suportam postos de trabalho a empregados de uma ou várias organizações (TREMBLAY, 2002; ROSENFIELD; DE ALVES, 2011);

(d) Trabalho móvel: trabalho longe do principal centro de trabalho e da moradia, por meio de viagens de negócios, trabalho de campo ou em instalações do cliente (ROSENFIELD; DE ALVES, 2011), sendo em geral lugares público, como um café ou em um meio de transporte (WOJCAK et al., 2016);

(e) Trabalho informal ou teletrabalho misto: arranjo que o empregado faz com o empregador para trabalhar algumas horas fora da empresa (ROSENFIELD; DE ALVES, 2011); 
Em relação ao tempo e periodicidade de teletrabalho (HADDON; BRYNIN, 2005) identificam-se as seguintes classificações: (i) parcialmente (AGUILERA et al., 2016), por meio de algumas horas do dia ou alguns dias da semana e (ii) totalmente, todos os dias em teletrabalho, podendo ter o horário fixado em horário comercial ou horário livre. Collins, Hislop e Cartwright (2016) perceberam que a maioria dos estudos acadêmicos está centrado no teletrabalhador em tempo parcial, sendo que os teletrabalhadores em tempo integral geralmente sofrem maiores impactos. Contudo, Wojcak et al. (2016) estima que o número de pessoas em teletrabalho, bem como as opções de teletrabalho a tempo integral e parcial, se alterem dinamicamente no futuro. Ainda, percebe-se que o teletrabalhador tem autonomia para gerir o tempo, mas, paradoxalmente, não tem controle sobre seu tempo de trabalho, pois este é definido pelo volume de trabalho, ou seja, é preciso responder às demandas de trabalho, sem restrição de tempo ou disponibilidade (ROSENFIELD; DE ALVES, 2011).

Sobre as Tecnologias da Informação e Comunicação (HADDON; BRYNIN, 2005), muitas já estão disponíveis para realização de teletrabalho. Contudo, embora a tecnologia tenha desempenhado um papel fundamental ao facilitar a adoção do teletrabalho, o acesso à internet e intranets da empresa pode ser difícil de se obter devido a limitações geográficas, assim como há muitas limitações de disponibilidade de informação trocadas por dispositivos ao invés da comunicação pessoal (BAYRAK, 2012).

Além disso, verifica-se a diferenciação de teletrabalho dependendo do tipo de contrato de trabalho que o colaborador possui. São duas as opções mais comuns: quando o trabalho é assalariado por uma organização ou quando é independente ou autônomo. Ou seja, ser colaborador de uma empresa e trabalhar para ela fora de seu escritório central, ou não estar associado diretamente a nenhuma organização (TREMBLAY, 2002).

Por último, infere-se que o tipo de atividades do trabalho é importante para que seja possível adotar o teletrabalho. Mokhtarian e Salomon (1994) identificam que a falta de adaptabilidade das tarefas tem sido uma restrição para a adoção do teletrabalho, contudo, essa dependência tende a acabar por meio do avanço tecnológico. Em suma, verifica-se a necessidade de trabalhos que possuam atividades com entregas definidas e haja interdependência de tarefas (BAILEY; KURLAND, 2002).

A Figura 1 apresenta as relações conceituais do teletrabalho: 
Figura 1 - Relações conceituais do teletrabalho

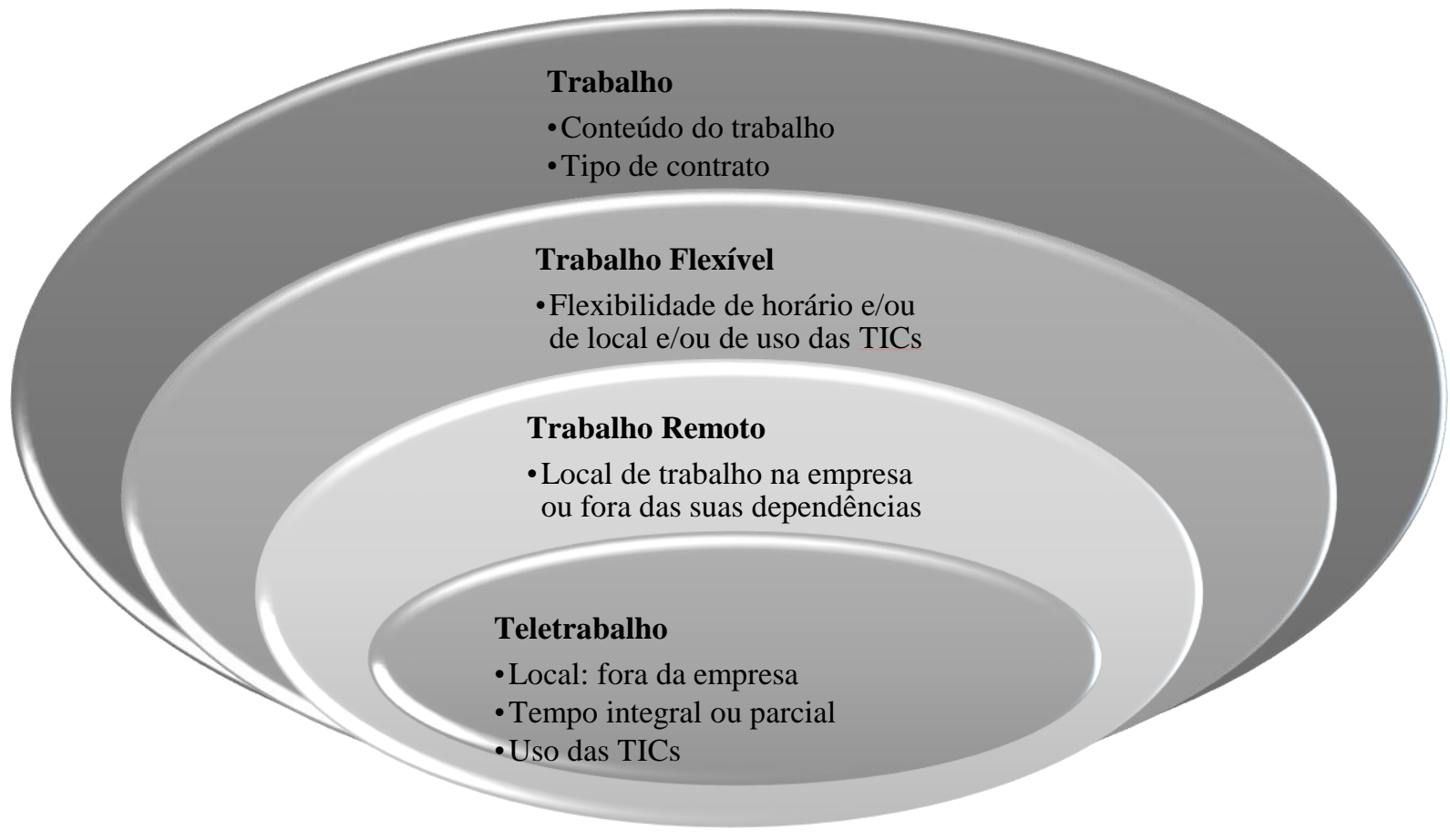

Fonte: elaboração própria, com base em Nogueira e Patini, 2012; Haddon e Brynin, 2005; Tremblay, 2002; Kugelmass, 1996.

O teletrabalho está inserido nas formas de trabalho flexível e remota, uma vez que traz a flexibilização do horário e localização por meio da utilização das TIC. Percebe-se que o termo teletrabalho possui diversas aplicações: tanto a um profissional em domicílio em tempo integral (podendo integrar também o trabalhador autônomo) quanto a um em tempo parcial ou a um teletrabalhador casual, que ocasionalmente exerce sua função em casa ou em outro lugar (TREMBLAY, 2002). Nota-se que a própria conceituação de teletrabalho ainda se mostra bastante heterogênea; existem diferentes nomenclaturas se referindo às mesmas práticas, bem como situações bastante divergentes referidas pelos mesmos termos (ROCHA; AMADOR, 2018).

Deve-se destacar que o teletrabalho possui impactos em diferentes atores: teletrabalhador (MOKHTARIAN; SALOMON, 1997), gestor de teletrabalhador (WOJCAK et al., 2016), equipe presencial (COENEN; KOK, 2014), família do teletrabalhador (SULLIVAN; LEWIS, 2011), a organização (ILLEGEMS; VERBEKE, 2004), organizações parceiras e sociedade. Além disso, o teletrabalho pode ser analisado de diferentes níveis e sistemas que são relacionados. De acordo com Bélanger, Watson-Manheim e Cisne (2013) há três subsistemas (subsistema pessoal, subsistema técnico e subsistema de estrutura organizacional) e três níveis 
de análise (individual, grupo e organizacional). Cada teletrabalhador individual, portanto, experimentará essa combinação de contextos de maneira diferente (BÉLANGER; WATSONMANHEIM; SWAN, 2013).

\section{METODOLOGIA}

Esta pesquisa é classificada como exploratória e descritiva, pois busca maior familiaridade com a produção científica internacional sobre teletrabalho. Utilizam-se, ainda, técnicas bibliométricas para identificar e descrever as informações encontradas por meio da quantificação. As análises bibliométricas têm como princípio gerar conhecimento quantitativo em determinadas áreas de pesquisa (ARAÚJO, 2006).

Ademais, o presente trabalho busca, por meio de uma revisão sistemática, identificar, selecionar e avaliar criticamente pesquisas relevantes sobre o teletrabalho e realizar uma interpretação dos textos quanto a seu alcance a determinados propósitos (CORDEIRO et al., 2007). Utiliza-se o método da revisão integrativa (BOTELHO; CUNHA; MACEDO, 2011), composto por etapas que permitem ao pesquisador aproximar-se da problemática que deseja apreciar, traçando um panorama sobre a sua produção científica, de forma que possa conhecer a evolução do tema ao longo do tempo e, com isso, visualizar possíveis oportunidades de pesquisa.

Na primeira etapa do processo de elaboração da revisão integrativa, ocorrem a definição de um problema e a formulação de uma pergunta de pesquisa, sendo estabelecida como: "o que tem sido pesquisado sobre o teletrabalho e seus impactos para as organizações? ". Com a pergunta de pesquisa definida, utilizou-se como descritores: "telework*”, "telecommuting" $e$

"home office" para a busca pelo título. Utilizou-se o conector OR entre as palavras, que muitas vezes são vistas como sinônimos na literatura sobre trabalho a distância. Assim, a busca foi feita nas bases de dados internacionalmente conhecidas: SCOPUS, EBSCO, Web of Science e Science Direct em 27 de janeiro de 2019.

A segunda etapa consiste na identificação dos estudos que serão incluídos ou excluídos na revisão. Utilizou-se como delimitador de pesquisa a necessidade de ter o texto completo em PDF e o tipo de documento ser artigo. Encontrou-se um portfólio de 302 artigos totais, na soma das bases de dados SCOPUS (49), EBSCO (80), Web of Science (73) e Science Direct (100). Com a exclusão dos artigos duplicados (48), restou um portfólio de 268 artigos. Não houve delimitação de horizonte temporal, assim, encontram-se artigos selecionados de 1984 a 2018. 
Na terceira etapa, realizou-se a leitura dos títulos, excluindo-se 68 por estarem alinhados em outras áreas da ciência. Continuou-se a leitura de resumos e palavras-chave, onde excluíram-se 76 artigos que não estavam em conformidade com a pergunta de pesquisa. Por fim, foi feita a leitura integral dos 110 artigos restantes, excluindo-se 61 por também não apresentarem conformidade com a pergunta de pesquisa, resultando em um portfólio de 49 artigos selecionados. A gestão dos artigos foi feita com o software Endnote. A figura 2 apresenta como os artigos foram selecionados.

Figura 2 - Descrição das etapas da revisão integrativa realizada

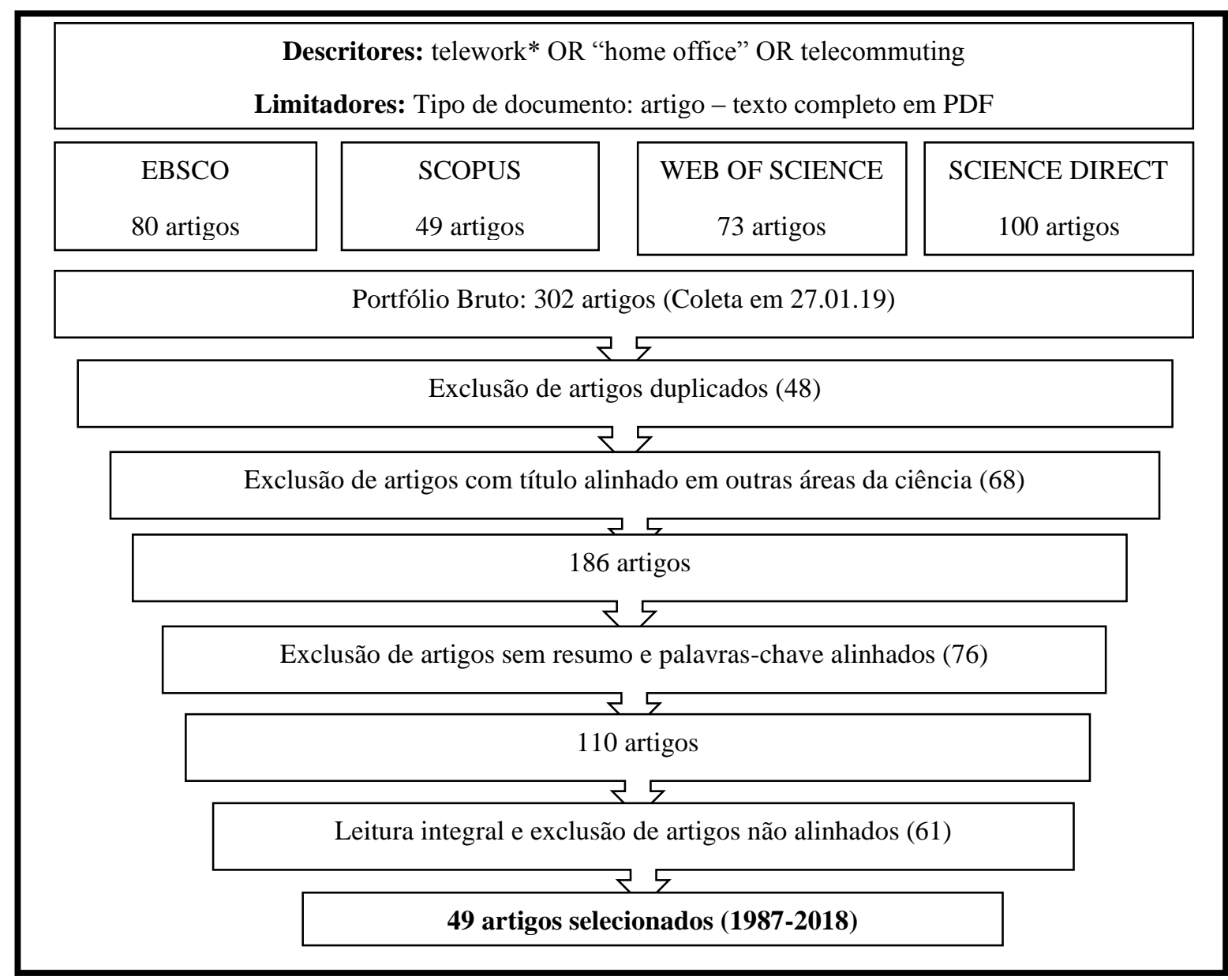

Fonte: elaboração própria.

A quarta etapa tem por objetivo sumarizar e documentar as informações extraídas dos artigos científicos encontrados nas fases anteriores. Essa documentação foi elaborada com as informações coletadas dos artigos: abordagem, ator estudado e nível de análise. Essas categorias analíticas foram utilizadas para facilitar a ordenação e a sumarização de cada estudo.

A quinta etapa busca apresentar a interpretação dos dados e, com isso, levantar as lacunas de conhecimento existentes e informações geradas pelos artigos em análise. A sexta 
etapa é composta por uma revisão, isto é, uma síntese do conhecimento levantado, com o intuito de propor caminhos para futuras pesquisas.

\section{ANÁLISE E DISCUSSÃO DOS RESULTADOS}

O portifólio de análise são os 49 artigos selecionados pela revisão integrativa. Verificase pelo gráfico 1, que há uma evolução histórica crescente de artigos publicados sobre o tema desde a década de 80, sendo o ano de 2012 com mais publicações.

Gráfico 1 - Evolução histórica de publicação dos artigos

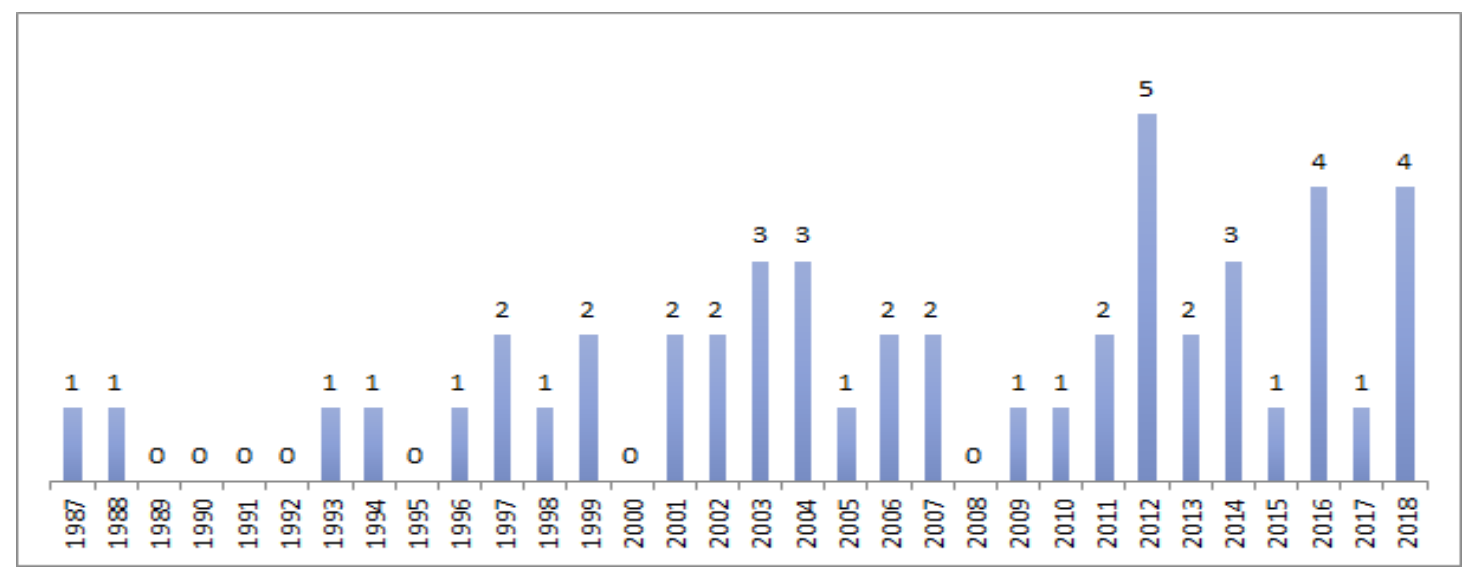

Fonte: elaboração própria.

Enfatiza-se que dos 49 artigos, 12 são de revisão da literatura, 23 artigos seguem uma abordagem quantitativa, 11 uma abordagem qualitativa e 3 artigos uma abordagem qualiquantitativa. No que tange aos artigos empíricos, apenas 4 artigos enfocam em organizações públicas, enquanto 13 artigos enfocam em organizações privadas, e o restante tratam de diversas organizações não citadas.

A fim de entender como o tema vem sendo tratado ao longo do tempo, buscou-se analisar os principais aspectos analisados sobre o tema ao longo dos anos. Ressalta-se que os assuntos referidos se repetem ao longo dos três períodos, sendo apresentado a seguir, apenas o foco de cada um:

1987-1998: são observados artigos mais concentrados em entender como a organização pode conseguir implementar o teletrabalho, ou seja, que aspectos são necessários analisar e ter para que aconteça o teletrabalho (KATZ, 1987; FROLICK; WILKES; URWILER, 1993; VAN SELL; JACOBS, 1994; FELDMAN; GAINEY, 1997). Além disso, verifica-se a publicação de artigos relacionadas a entender a preferência do colaborador e a tomada de decisão em aderir a 
essa nova forma de trabalho ou não (MOKHTARIAN; SALOMON, 1997; TEO; LIM; WAI, 1998) tendo em vista a sua utilidade (NILLES, 1988).

2001-2009: percebe-se, nesse período, maior ênfase na análise do impacto que o teletrabalho pode trazer ao colaborador que utiliza essa modalidade (VITTERS $\varnothing$ et al., 2003), sobretudo no contexto trabalho família (SULLIVAN; LEWIS, 2001; KOSSEK; LAUTSCH; EATON, 2006; MARUYAMA; HOPKINSON; JAMES, 2009). Também é verificado artigos analisando em conjunto impacto desse modelo laboral ao profissional praticante e a organização (HILL; FERRIS; MÄRTINSON, 2003; ILLEGEMS; VERBEKE, 2004)

2010-2018: nesse período, aparece uma mescla do assuntos já dispostos. Contudo, o tema mais ocorrido é o impacto do teletrabalho na organização em relação a comprometimento organizacional (HUNTON; NORMAN, 2010), produtividade (DUTCHER, 2012), desempenho organizacional (COENEN; KOK, 2014), estratégias (COOKE; CHOWHAN; COOPER, 2014), sustentabilidade (CONTREAS; ROJAS, 2015), liderança (WOJCAK et al., 2016) e controle (GROEN et al., 2018).

Os países com mais publicações foram: Estados Unidos (17), Reino Unido (5), Canadá (4) e Holanda (4). Brasil possui três artigos publicados no portifólio analisado. As publicações dos Estados Unidos advêm de diferentes 24 universidades. Ademais, destaca-se a University of Amsterdam com 3 publicações, e a Vrije Universiteit Brussel com 2 publicações. As revistas que mais publicaram artigos sobre o tema são apresentadas no Quadro 2:

Quadro 2 - Distribuição de artigos publicados por revista

\begin{tabular}{|l|l|l|}
\hline \multicolumn{1}{|c|}{ Revista } & Qualis & Quantidade \\
\hline Journal of vocational behavior & $\mathrm{A} 1$ & 4 \\
\hline Information \& Management & $\mathrm{A} 1$ & 3 \\
\hline New Technology, Work and Employment & $\mathrm{A} 1$ & 3 \\
\hline Transportation Research & $\mathrm{A} 1$ & 3 \\
\hline European Management Journal & $\mathrm{A} 1$ & 2 \\
\hline International Journal of Information Management & $\mathrm{A} 1$ & 2 \\
\hline Telematics and Informatics & $\mathrm{A} 1$ & 2 \\
\hline
\end{tabular}

Fonte: elaboração própria.

Percebe-se que todos os periódicos que publicaram acima de um artigo, possuem o conceito mais alto da Classificações de Periódicos Qualis no quadriênio de 2013 a 2016, embora tenham poucas publicações no total. A seguir apresenta-se no Quadro 3 os artigos mais citados (acima de 100 citações) de acordo com o Google Acadêmico:

Quadro 3 - Artigos mais citados

Artigos mais citados 


\begin{tabular}{|c|c|c|c|c|}
\hline Citações & Ano & Autores & Título do artigo & $\begin{array}{l}\text { Países dos } \\
\text { autores }\end{array}$ \\
\hline 684 & 2006 & $\begin{array}{l}\text { Kossek, } \\
\text { Lautsch, } \\
\text { Eaton }\end{array}$ & $\begin{array}{l}\text { Telecommuting, control, and boundary management: } \\
\text { Correlates of policy use and practice, job control, and } \\
\text { work-family effectiveness }\end{array}$ & $\begin{array}{l}\text { Estados } \\
\text { Unidos e } \\
\text { Canadá }\end{array}$ \\
\hline 472 & 2003 & $\begin{array}{l}\text { Hill, } \\
\text { Ferris, } \\
\text { Märtinson }\end{array}$ & $\begin{array}{c}\text { Does it matter where you work? A comparison of how } \\
\text { three work venues (traditional office, virtual office, } \\
\text { and home office) influence aspects of work and } \\
\text { personal/family life }\end{array}$ & $\begin{array}{l}\text { Estados } \\
\text { Unidos }\end{array}$ \\
\hline 299 & 1997 & $\begin{array}{l}\text { Mokhtaria } \\
\text { n, Salomon }\end{array}$ & $\begin{array}{l}\text { Modeling the desire to telecommute: The importance } \\
\text { of attitudinal factors in behavioral models }\end{array}$ & $\begin{array}{l}\text { Estados } \\
\text { Unidos e } \\
\text { Israel }\end{array}$ \\
\hline 298 & 2001 & $\begin{array}{l}\text { Sullivan, } \\
\text { Lewis }\end{array}$ & $\begin{array}{l}\text { Home-based Telework, Gender, and the } \\
\text { Synchronization of Work and Family: Perspectives of } \\
\text { Teleworkers and their Co-residents }\end{array}$ & $\begin{array}{l}\text { Reino } \\
\text { Unido }\end{array}$ \\
\hline 274 & 1999 & Bélanger & $\begin{array}{l}\text { Workers' propensity to telecommute: An empirical } \\
\text { study }\end{array}$ & $\begin{array}{l}\text { Estados } \\
\text { Unidos }\end{array}$ \\
\hline 230 & 1988 & Nilles & $\begin{array}{c}\text { Traffic reduction by telecommuting: A status review } \\
\text { and selected bibliography }\end{array}$ & $\begin{array}{l}\text { Estados } \\
\text { Unidos }\end{array}$ \\
\hline 189 & 2002 & $\begin{array}{l}\text { Kurland, } \\
\text { Cooper }\end{array}$ & $\begin{array}{l}\text { Manager control and employee isolation in } \\
\text { telecommuting environments }\end{array}$ & $\begin{array}{l}\text { Estados } \\
\text { Unidos }\end{array}$ \\
\hline 177 & 2004 & $\begin{array}{l}\text { Peters, } \\
\text { Tijdens, } \\
\text { Wetzels }\end{array}$ & $\begin{array}{c}\text { Employees' opportunities, preferences, and practices } \\
\text { in telecommuting adoption }\end{array}$ & Holanda \\
\hline 166 & 2006 & Golden & $\begin{array}{l}\text { Avoiding depletion in virtual work: Telework and the } \\
\text { intervening impact of work exhaustion on } \\
\text { commitment and turnover intentions }\end{array}$ & $\begin{array}{l}\text { Estados } \\
\text { Unidos }\end{array}$ \\
\hline 157 & 1997 & $\begin{array}{l}\text { Feldman, } \\
\text { Gainey }\end{array}$ & $\begin{array}{c}\text { Patterns of telecommuting and their consequences: } \\
\text { Framing the research agenda }\end{array}$ & $\begin{array}{l}\text { Estados } \\
\text { Unidos }\end{array}$ \\
\hline 150 & 2003 & $\begin{array}{l}\text { Workman, } \\
\text { Kahnweile } \\
\text { r, Bommer }\end{array}$ & $\begin{array}{l}\text { The effects of cognitive style and media richness on } \\
\text { commitment to telework and virtual teams }\end{array}$ & $\begin{array}{l}\text { Estados } \\
\text { Unidos }\end{array}$ \\
\hline 148 & 1999 & $\begin{array}{c}\text { Duxbury, } \\
\text { Neufeld }\end{array}$ & $\begin{array}{l}\text { An empirical evaluation of the impacts of } \\
\text { telecommuting on intra-organizational communication }\end{array}$ & Canadá \\
\hline 122 & 2005 & $\begin{array}{l}\text { Haddon, } \\
\text { Brynin }\end{array}$ & $\begin{array}{l}\text { The character of telework and the characteristics of } \\
\text { teleworkers }\end{array}$ & $\begin{array}{l}\text { Reino } \\
\text { Unido }\end{array}$ \\
\hline 120 & 2004 & $\begin{array}{l}\text { Illegems, } \\
\text { Verbeke }\end{array}$ & Telework: What Does it Mean for Management? & $\begin{array}{l}\text { Bélgica e } \\
\text { Reino } \\
\text { Unido }\end{array}$ \\
\hline
\end{tabular}

Fonte: elaboração própria.

Verifica-se que os países com mais publicações são os que são mais vezes citados, sendo perceptível que os Estados Unidos possuem certa liderança na publicações sobre o tema. Destacam-se parcerias entre países como, Estados Unidos e Canadá, Estados Unidos e Israel, e ainda, Bélgica e Reino Unido. Em sua revisão sistemática, Da Silva (2014) verificou que as 
pesquisas mais relevantes, de acordo com o número de citações, são de países anglo-saxônicos (Estados Unidos, Canadá e Inglaterra, respectivamente); como também que havia pouca pesquisa em parceria internacional.

$\mathrm{O}$ artigo mais citado discorre sobre gerenciamento e controle de teletrabalho e os limites entre trabalho e família (KOSSEK; LAUTSCH; EATON, 2006), seguido por outros que apresentam características do teletrabalho (HILL; FERRIS; MÄRTINSON, 2003; HADDON; BRYNIN, 2005) e seu impacto à organização (FELDMAN; GAINEY, 1997; DUXBURY; NEUFELD, 1999; WORKMAN; KAHNWEILER; BOMMER, 2003; ILLEGEMS; VERBEKE, 2004; GOLDEN, 2006), à vida dos teletrabalhadores (KURLAND; COOPER, 2002; PETERS; TIJDENS; WETZELS, 2004), ao gestor de teletrabalhador (WOJCAK et al., 2016), à equipe presencial (COENEN; KOK, 2014) e à família do teletrabalhador (SULLIVAN; LEWIS, 2011; BÉLANGER; WATSON-MANHEIM; SWAN, 2013).

No que tange as palavras-chave dos artigos, observa-se que o termo mais utilizado foi o telework e telecommuting, seguido por palavras relacionadas ao tema como: trabalho, flexibilidade, tecnologia, casa, mobilidade. Observou-se que 11 artigos não tinham palavraschave definidas, enquanto os que tinham, utilizavam cerca de três a seis palavras-chave. Apresenta-se a figura 3, com as palavras-chaves mais utilizadas nos artigos:

Figura 3 - Palavras-chave utilizadas nos artigos selecionados

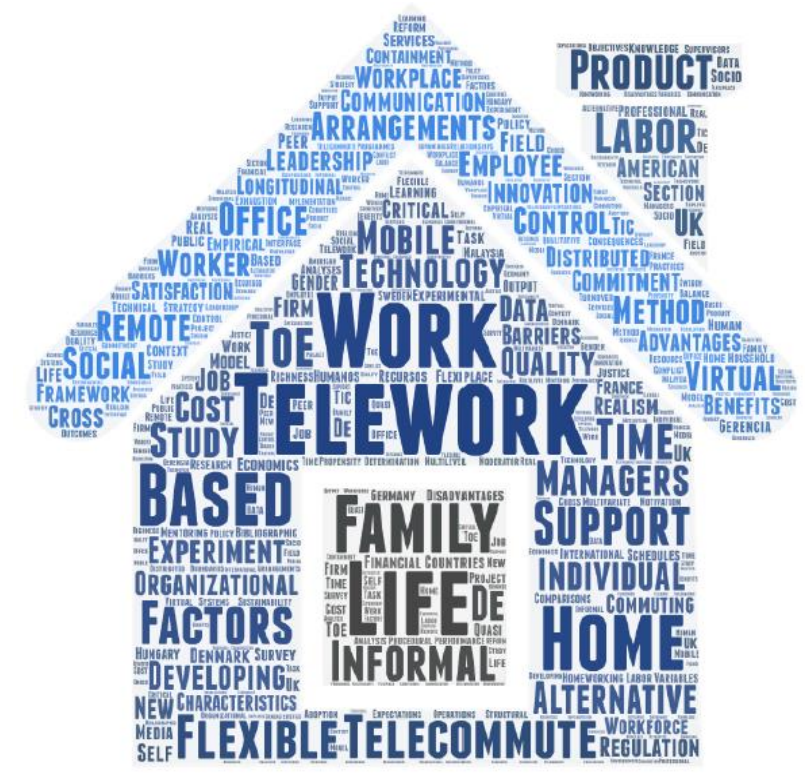

Fonte: elaboração própria. 
Em relação ao conteúdo dos artigos de revisão encontrados percebe-se forte busca por condutores e barreiras organizacionais, como tecnologias da informação (TUNG; TURBAN, 1996; BAYRAK, 2012), liderança (WOJCAK et al., 2016), propostas de trabalho (FELDMAN; GAINEY, 1997), políticas da organização (VAN DEN BROEK; KEATING, 2011) e condutores e barreiras externos, como a legislação (HAZAN; MORATO, 2018). Ainda, notase a análise de impactos do teletrabalho em nível pessoal (VAN SELL; JACOBS, 1994) e organizacional (NILLES, 1988; CONTRERAS; ROJAS, 2015). Há, também, abordagem e discussão conceitual (BÉLANGER; WATSON-MANHEIM; SWAN, 2013) identificando os multiníveis de análise que podem ser utilizados no teletrabalho. Em maior escala, a identificação de informações dos artigos é feita no subsistema organizacional, seguido pelo subsistema pessoal, e, em menor escala, subsistema técnico.

No que diz respeito aos poucos artigos empíricos no setor público encontrados, constatase que estão voltados à busca de impactos gerados (DUXBURY; NEUFEL, 1999; SOLÍS, 2017; HAU; TODESCAT, 2018) e têm estendido maior preocupação a diferentes atores como o colaborador, gestor, colegas de trabalho, interação em meio social (COLLINS; HISLOP; CARTWRIGHT, 2016) e com a família (SOLÍS, 2017).

Aos demais artigos, verifica-se que o foco é a busca por barreiras e condutores ao teletrabalho, isto é, aspectos que facilitam ou não a introdução desse modelo laboral em nível pessoal/profissional (MOKHTARIAN; SALOMON, 1997; BÉLANGER, 1999; PETERS; TIJDENS; WETZELS, 2004) e organizacional (PÉREZ; SÁNCHEZ; CARNICER, 2002; ANSONG; BOATENG, 2018). A gestão também tem sido discutida pelos artigos, no que tange ao controle (KURLAND; COOPER, 2002; GROEN et al., 2018), estratégias para implantação de teletrabalho (COOKE; CHOWHAN; COOPER, 2014) e identificação de variáveis a serem avaliadas para uma implementação do teletrabalho (KATZ, 1987; VARGAS; OSMA, 2013).

O destaque da grande maioria dos artigos é seu foco no impacto do teletrabalho, ou seja, a mudança que gera a diferentes aspectos de diversos atores envolvidos: no nível pessoal (MARUYAMA; HOPKINSON; JAMES, 2009; ABDULLAH; ISMAIL, 2012; CAMPBELL; HEALES, 2016), em relações familiares (SULLIVAN; LEWIS, 2001; KOSSEK; LAUTSCH; EATON, 2006), e no nível organizacional (FROLICK; WILKES; URWILER, 1993; ILLEGEMS; VERBEKE, 2004; HUNTON; NORMAN, 2010), como por exemplo, impacto no acesso ao conhecimento (LEE; SHIN; HIGA, 2007) e na produtividade (NEIROTTI; PAOLUCCI; RAGUSEO, 2012; DUTCHER, 2012). 
A seguir serão apresentados as barreiras e os condutores mais citados em relação ao teletrabalho, e, ainda, os impactos gerados por esse novo modelo de trabalho. O Quadro 4 apresenta o resumo das principais barreiras e condutores relacionados ao teletrabalho:

Quadro 4 - Barreiras e condutores à adoção do teletrabalho

\begin{tabular}{|c|c|c|}
\hline Categorias & Barreiras & Condutores \\
\hline \multirow[b]{2}{*}{ Informacionais } & $\begin{array}{l}\begin{array}{l}\text { A ausência de conhecimento do } \\
\text { "teletrabalho" } \\
\text { (ILLEGEMS; } \\
\text { S'JEGERS, 2001) }\end{array} \\
\end{array}$ & \multirow{2}{*}{$\begin{array}{l}\text { Colaboradores com um nível de } \\
\text { ensino elevado (ILLEGEMS; } \\
\text { VERBEKE; S'JEGERS, 2001) }\end{array}$} \\
\hline & $\begin{array}{l}\text { Falta de legislação específica e formalização da } \\
\text { modalidade (ILLEGEMS; VERBEKE; S'JEGERS, } \\
\text { 2001; ILLEGEMS; VERBEKE, 2004; HAU; } \\
\text { TODESCAT, 2018) }\end{array}$ & \\
\hline \multirow{4}{*}{ Organizacionais } & $\begin{array}{l}\text { Cultura organizacional (CONTRERAS; ROJAS, } \\
\text { 2015; HAU; TODESCAT, 2018) }\end{array}$ & $\begin{array}{l}\text { Empresas de setor baseado no } \\
\text { conhecimento } \\
\text { VERBEKE; S'JEGERS, 2001) }\end{array}$ \\
\hline & Baixa comunicação (WOJCAK et al., 2016). & $\begin{array}{llr}\text { Alto nível de } & \text { comunicação } \\
\text { (ILLEGEMS; } & \text { VERBEKE; } \\
\text { S'JEGERS, 2001) } & \\
\end{array}$ \\
\hline & $\begin{array}{l}\text { Adaptação à mudança e estilo de liderança } \\
\text { (CONTRERAS; ROJAS, 2015) }\end{array}$ & $\begin{array}{l}\text { Coordenação e sistemas de controle } \\
\text { orientados para a produção e } \\
\text { resultados } \\
\text { VERBEKE; S'JEGERS, 2001) }\end{array}$ \\
\hline & $\begin{array}{l}\text { Resistência entre os gestores que utilizam métodos } \\
\text { tradicionais de controle e coordenação (VAN SELL; } \\
\text { JACOBS, 1994; ILLEGEMS; VERBEKE; } \\
\text { S'JEGERS, 2001) }\end{array}$ & $\begin{array}{l}\text { Práticas de gestão adequadas } \\
\text { desenvolvidas nas organizações } \\
\text { (CONTRERAS; ROJAS, 2015) }\end{array}$ \\
\hline \multirow{2}{*}{$\begin{array}{lr}\text { Tecnologias } & \text { da } \\
\text { Informação } & \text { e } \\
\text { Comunicação } & \end{array}$} & $\begin{array}{llr}\begin{array}{l}\text { Adaptação } \\
\text { (PÉREZ; }\end{array} \text { SÁNClógica e } & \text { investimento } & \text { inicial } \\
\text { CONTRERAS; ROJAS, 2015) } & \text { CARNICER, } & \text { 2002; } \\
\text { CONTRER }\end{array}$ & \multirow{2}{*}{$\begin{array}{l}\text { Uso bem desenvolvido das } \\
\text { Tecnologias da } \\
\text { (PÉREZ; } \\
\text { CARNICER, 2002) }\end{array}$} \\
\hline & $\begin{array}{l}\text { Qualidade baixa das telecomunicações em } \\
\text { determinadas regiões (CONTRERAS; ROJAS, } \\
\text { 2015) }\end{array}$ & \\
\hline
\end{tabular}

Fonte: elaboração própria.

Além dos condutores e barreiras ao teletrabalho, ainda há espaço para pesquisas avançando na direção do impacto do teletrabalho dentro das organizações (DA SILVA, 2014). O teletrabalho possui muitas peculiaridades a serem estudadas e desenvolvidas, visto que muitas vezes, são encontrados resultados contraditórios. Por exemplo, Hau e Todescat (2018) observaram que a maioria dos teletrabalhadores analisados estavam satisfeitos nas áreas pessoal e familiar, enquanto Hill, Ferris Märtinson (2003) verificaram que os teletrabalhadores relataram significativamente menos sucesso pessoal e familiar que os não teletrabalhadores.

Os impactos benéficos do teletrabalho podem ser atribuídos a três atores principais: teletrabalhador, organização e sociedade. A respeito das vantagens auferidas aos teletrabalhadores, apresenta-se o Quadro 5: 
Quadro 5 - Benefícios na implementação do teletrabalho ao teletrabalhador

\begin{tabular}{|c|c|}
\hline \multicolumn{2}{|r|}{ Benefícios } \\
\hline \multirow{3}{*}{ Deslocamento } & $\begin{array}{l}\text { Evita o deslocamento (TEO; LIM; WAI, 1998; MARUYAMA; HOPKINSON; TIAGO, } \\
\text { 2009; TREMBLAY; THOMSIN, 2012; HAU; TODESCAT, 2018; ANSONG; } \\
\text { BOATENG, 2018) }\end{array}$ \\
\hline & Evita o estresse com deslocamento (HAU; TODESCAT, 2018) \\
\hline & Reduz o gasto com deslocamento (HAZAN; MORATO, 2018) \\
\hline \multirow{4}{*}{ Pessoal } & Gera maior convívio familiar (HAZAN; MORATO, 2018) \\
\hline & $\begin{array}{l}\text { Propicia a organização do Tempo Livre (HAU; TODESCAT, 2018; ANSONG; } \\
\text { BOATENG, 2018) }\end{array}$ \\
\hline & $\begin{array}{l}\text { Propicia o equilíbrio entre trabalho e família (ILLEGEMS; VERBEKE; S'JEGERS, } \\
\text { 2001; TREMBLAY; THOMSIN, 2012; ABDULLAH; ISMAIL, 2012) }\end{array}$ \\
\hline & Gera melhoria na vida social (ANSONG; BOATENG, 2018) \\
\hline \multirow{6}{*}{ Profissional } & Reduz as interferências dos colegas (TREMBLAY; THOMSIN, 2012) \\
\hline & Gera o sentimento de ser um profissional responsável (TEO; LIM; WAI, 1998) \\
\hline & $\begin{array}{l}\text { Agrega flexibilidade de horário (TREMBLAY; THOMSIN, 2012) sendo possível a } \\
\text { realizar o trabalho no horário que for mais produtivo (TEO; LIM; WAI, 1998) }\end{array}$ \\
\hline & $\begin{array}{l}\text { Aumenta a qualidade de vida no trabalho (TEO; LIM; WAI, 1998; ABDULLAH; } \\
\text { ISMAIL, 2012; HAU; TODESCAT, 2018) }\end{array}$ \\
\hline & Aumenta a satisfação do trabalho (ABDULLAH; ISMAIL, 2012) \\
\hline & Reduz o estresse (VAN SELL; JACOBS, 1994; TREMBLAY; THOMSIN, 2012) \\
\hline \multirow[b]{2}{*}{ Desenvolvimento } & $\begin{array}{l}\text { Gera desenvolvimento pessoal e crescimento profissional (TREMBLAY; THOMSIN, } \\
\text { 2012) }\end{array}$ \\
\hline & $\begin{array}{l}\text { Melhora as competências individuais, tais como: amadurecimento profissional, } \\
\text { responsabilidade, agilidade, proatividade (ADERALDO; ADERALDO; LIMA, 2017), } \\
\text { autonomia (TEO; LIM; WAI, 1998; DA COSTA, 2005) e aumento de eficiência } \\
\text { (TREMBLAY; THOMSIN, 2012) }\end{array}$ \\
\hline
\end{tabular}

Fonte: elaboração própria.

Destaca-se o benefício da redução de deslocamento como sendo o mais citado. Além disso, classificou-se vantagens percebidas em nível pessoal e em nível profissional. Os benefícios de desenvolvimento, por sua vez, referem-se ao desenvolvimento de características tanto pessoais como profissionais motivadas pelo teletrabalho. Ademais, o teletrabalho gera benefícios a organização (Quadro 6):

Quadro 6 - Benefícios da implementação do teletrabalho a organização

\begin{tabular}{|l|l|}
\hline \multicolumn{1}{|l|}{ Denefícios } & $\begin{array}{l}\text { Aumenta a motivação (ILLEGEMS; VERBEKE, 2004) e o comprometimento } \\
\text { organizacional (DOURADO, 2006) }\end{array}$ \\
\cline { 2 - 3 } & $\begin{array}{l}\text { Aumenta a produtividade (VAN SELL; JACOBS, 1994; ILLEGEMS; VERBEKE; } \\
\text { S'JEGERS, 2001; ILLEGEMS; VERBEKE, 2004; ANSONG; BOATENG, 2018; } \\
\text { HAZAN; MORATO, 2018) }\end{array}$ \\
\hline \multirow{2}{*}{$\begin{array}{l}\text { Pestão } \\
\text { de }\end{array}$} & $\begin{array}{l}\text { Aumenta a retenção (ILLEGEMS; VERBEKE; S'JEGERS, 2001; ILLEGEMS; } \\
\text { VERBEKE, 2004; DOURADO, 2006; KOSSEK; LAUTSCH; EATON, 2006; } \\
\text { ABDULLAH; ISMAIL, 2012) }\end{array}$ \\
\cline { 2 - 3 } & $\begin{array}{l}\text { Reduz o absenteísmo (ILLEGEMS; VERBEKE; S'JEGERS, 2001; ILLEGEMS; } \\
\text { VERBEKE, 2004; ANSONG; BOATENG, 2018) }\end{array}$ \\
\hline
\end{tabular}


(CONTINUAÇÃO)

\begin{tabular}{|l|l|}
\hline & $\begin{array}{l}\text { Melhora o recrutamento (FELDMAN; GAINEY, 1997; ILLEGEMS; VERBEKE; } \\
\text { S'JEGERS, 2001; ILLEGEMS; VERBEKE, 2004) uma vez que melhora a imagem da } \\
\text { empresa e possibilita a integração de pessoas com deficiência (ILLEGEMS; VERBEKE; } \\
\\
\text { S'JEGERS, 2001; ILLEGEMS; VERBEKE, 2004) }\end{array}$ \\
\hline \multirow{3}{*}{ Espaço físico } & $\begin{array}{l}\text { Reduz os gastos no escritório (eletricidade, água, papel) (HAZAN; MORATO, 2018; } \\
\text { ANSONG; BOATENG, 2018) }\end{array}$ \\
\cline { 2 - 2 } & Soluciona a falta de espaço (ILLEGEMS; VERBEKE; S'JEGERS, 2001) \\
\hline
\end{tabular}

Fonte: elaboração própria.

Organizou-se os achados da literatura em três ganhos principais a organização: melhoria de desempenho de profissionais, melhoria em indicadores de gestão de pessoas e melhoria de aproveitamento de espaço físico. Por fim, a sociedade também se beneficia com a implementação de programas de teletrabalho à medida que há a redução na emissão de poluentes e redução de uso do papel (HAZAN; MORATO, 2018).

O teletrabalho tem a capacidade, ainda, de gerar impactos negativos a organização quando não corretamente implementado. Para o teletrabalhador, pode haver fragilidades no nível pessoal e profissional (Quadro 7):

Quadro 7 - Fragilidades da implementação do teletrabalho ao teletrabalhador

\begin{tabular}{|c|c|}
\hline & Fragilidades \\
\hline \multirow{5}{*}{ Pessoal } & $\begin{array}{l}\text { Interações sociais reduzidas e isolamento social (ILLEGEM; VERBEKE; S'JEGERS, 2001), } \\
\text { o que aumenta ao longo do tempo, principalmente na modalidade integral (TREMBLAY, } \\
\text { 2002; COLLINS; HISLOP; CARTWRIGHT, 2016) }\end{array}$ \\
\hline & Invasão do espaço familiar (DA COSTA, 2007) \\
\hline & Distração com a família ou com atividades domésticas (HAZAN; MORATO, 2018) \\
\hline & $\begin{array}{l}\text { Transferência de custos (DA COSTA, 2007; TREMBLAY; THOMSIN, 2012) de } \\
\text { disponibilidade de equipamentos e recursos de trabalho (ILLEGEMS; VERBEKE, 2004) }\end{array}$ \\
\hline & Visão preconceituosa das pessoas (HAU; TODESCAT, 2018) \\
\hline \multirow{9}{*}{ Profissional } & Insegurança no trabalho por falta de regulamento (HAZAN; MORATO, 2018) \\
\hline & Espaço no trabalho reduzido (TEO; LIM; WAI, 1998) \\
\hline & $\begin{array}{l}\text { Redução da possibilidade de promoção (TEO; LIM; WAI, 1998; ILLEGEMS; VERBEKE; } \\
\text { S'JEGERS, 2001) e consequentemente, oportunidade de carreira reduzida (ILLEGEMS; } \\
\text { VERBEKE, 2004; HAU; TODESCAT, 2018) }\end{array}$ \\
\hline & $\begin{array}{l}\text { Aumento de pressão (TREMBLAY; THOMSIN, 2012), de horas trabalhadas (DA COSTA, } \\
\text { 2007) gerando exaustão do trabalho (DOURADO, 2006) e mais cansaço no final do dia } \\
\text { (TREMBLAY; THOMSIN, 2012) }\end{array}$ \\
\hline & $\begin{array}{l}\text { Redução de convívio social (HAZAN; MORATO, 2018) e interação profissional } \\
\text { (ILLEGEMS; VERBEKE, 2004) }\end{array}$ \\
\hline & Individualização do trabalho (ROCHA; AMADOR, 2018) \\
\hline & Perda de espírito de equipe (TREMBLAY; THOMSIN, 2012) \\
\hline & $\begin{array}{l}\text { Dificuldade de participação em geração de ideias, discussão, análise e decisões (TUNG; } \\
\text { TURBAN, 1996) }\end{array}$ \\
\hline & $\begin{array}{l}\text { Dificuldade de criação de relações com pessoas que já não são conhecidas antes de entrar em } \\
\text { teletrabalho (COLLINS; HISLOP; CARTWRIGHT, 2016) }\end{array}$ \\
\hline
\end{tabular}

Fonte: elaboração própria. 
Assim, um desafio marcante no teletrabalho é a diminuição de contato pessoal fazendo com que haja isolamento. No que diz respeito as fragilidades organizacionais em relação ao teletrabalho, apresenta-se o Quadro 8:

Quadro 8 - Fragilidades da implementação do teletrabalho a organização

\begin{tabular}{|c|c|}
\hline & Fragilidades \\
\hline \multirow{2}{*}{$\begin{array}{l}\text { Tecnologias da } \\
\text { Informação } \\
\text { Comunicação }\end{array}$} & $\begin{array}{l}\text { Investimento caro em tecnologias da informação e comunicação (ILLEGEMS; } \\
\text { VERBEKE; S'JEGERS, 2001; ILLEGEMS; VERBEKE, 2004) }\end{array}$ \\
\hline & $\begin{array}{l}\text { Falta de segurança e vulnerabilidade de dados internos (ILLEGEMS; VERBEKE; } \\
\text { S'JEGERS, 2001; ILLEGEMS; VERBEKE, 2004; HAZAN; MORATO, 2018; HAU; } \\
\text { TODESCAT, 2018) }\end{array}$ \\
\hline \multirow{3}{*}{$\begin{array}{l}\text { Gestão } \\
\text { Pessoas }\end{array}$} & $\begin{array}{l}\text { Desafio para o gestor na forma de gerir teletrabalhadores e pessoas que permanecem no } \\
\text { local de trabalho (PÉREZ; SÁNCHEZ; CARNICER, 2002) }\end{array}$ \\
\hline & Dificuldade de controle de performance (TUNG; TURBAN, 1996) \\
\hline & $\begin{array}{l}\text { Efeitos negativos na cultura organizacional pela visão dos não teletrabalhadores } \\
\text { (ILLEGEMS; VERBEKE, 2004) }\end{array}$ \\
\hline \multirow{3}{*}{$\begin{array}{l}\text { Desempenho de } \\
\text { atividades }\end{array}$} & O risco de perder ambientes criativos com colaboração (CONTRERAS; ROJAS, 2015) \\
\hline & $\begin{array}{l}\text { Dificuldade de execução de atividades que requerem contato cara a cara (ILLEGEMS; } \\
\text { VERBEKE, 2004) }\end{array}$ \\
\hline & $\begin{array}{l}\text { Dificuldade de desenvolvimento de trabalho em equipe (ILLEGEMS; VERBEKE; } \\
\text { S'JEGERS, 2001; ILLEGEMS; VERBEKE, 2004) }\end{array}$ \\
\hline
\end{tabular}

Fonte: elaboração própria.

Os desafios detectados foram divididos em três blocos: em relação as tecnologias da informação, a gestão de pessoas e o desempenho de atividades. Tendo isso em vista, Aderaldo, Aderaldo e Lima (2017) verificam que a minimização dos problemas derivados do teletrabalho, tanto para as organizações quanto para os indivíduos, está ao alcance dos líderes e dos trabalhadores. Para que isto ocorra enquanto estratégia de desenvolvimento das pessoas e da organização, as tarefas, práticas, processos e comunicação no regime de teletrabalho devem ser integrados à cultura organizacional e à estrutura tecnológica oferecida (ADERALDO; ADERALDO; LIMA, 2017).

\section{CONSIDERAÇÕES FINAIS}

A presente revisão integrativa da literatura internacional teve como objetivo analisar a produção científica disponível em bases de dados internacionais acerca do teletrabalho, modalidade laboral crescente nos últimos anos (ROCHA; AMADOR, 2018). Em termos específicos, buscou-se: analisar o volume da produção científica acerca do teletrabalho; identificar, a partir da literatura, os impactos do teletrabalho nas organizações; e identificar o foco de estudo dos artigos. 
A produção científica sobre o tema vem crescendo ao longo dos anos desde a década de 80. Observa-se a grande quantidade de artigos de revisão (12) encontrados no portifólio de análise. Em relação aos artigos empíricos, nota-se a baixa quantidade de pesquisas em organização públicas. A maioria dos artigos seguem uma abordagem quantitativa e advém de diferentes países. Estados Unidos e Reino Unido lideram o ranque de quantidade de publicações, assim como a lista dos artigos mais citados. Destaca-se a University of Amsterdam que possui três publicações das quatro efetuadas pela Holanda. As palavras-chave mais utilizadas para o tema são telework e telecommuting.

O foco dos estudos nitidamente está na busca de impactos causados pela implementação do teletrabalho. Percebe-se que impacto é gerado em diferentes atores: no nível pessoal (MARUYAMA; HOPKINSON; JAMES, 2009; ABDULLAH; ISMAIL, 2012; CAMPBELL; HEALES, 2016), em relações familiares (SULLIVAN; LEWIS, 2001; KOSSEK; LAUTSCH; EATON, 2006), e no nível organizacional (FROLICK; WILKES; URWILER, 1993; ILLEGEMS; VERBEKE, 2004; HUNTON; NORMAN, 2010), como por exemplo, impacto no acesso ao conhecimento (LEE; SHIN; HIGA, 2007) e na produtividade (NEIROTTI; PAOLUCCI; RAGUSEO, 2012; DUTCHER, 2012). A gestão também tem sido discutida pelos artigos, no que tange ao controle (KURLAND; COOPER, 2002; GROEN et al., 2018), estratégias para implantação de teletrabalho (COOKE; CHOWHAN; COOPER, 2014) e identificação de variáveis a serem avaliadas para uma implementação efetiva de teletrabalho (KATZ, 1987; VARGAS; OSMA, 2013). Ainda, em relação ao conteúdo dos artigos de revisão encontrados, percebe-se forte busca por condutores e barreiras organizacionais, como tecnologias da informação (TUNG; TURBAN, 1996; BAYRAK, 2012), liderança (WOJCAK et al., 2016), propostas de trabalho (FELDMAN; GAINEY, 1997), políticas da organização (VAN DEN BROEK; KEATING, 2011) e condutores e barreiras externos, como a legislação (HAZAN; MORATO, 2018).

Os impactos do teletrabalho foram relacionados a três atores principais: teletrabalhador, organização e sociedade. Ao teletrabalhador, impactos positivos são verificados na dispensa de deslocamento (TREMBLAY; THOMSIN, 2012), maior convívio familiar (HAZAN; MORATO, 2018) e melhoria de desempenho (TREMBLAY; THOMSIN, 2012), enquanto os negativos pairam sobre o isolamento social (ILLEGEM; VERBEKE; S'JEGERS, 2001) e individualização do trabalho (ROCHA; AMADOR, 2018). Sobre os impactos à organização, observa-se benefícios no que tange a melhoria no recrutamento, seleção e retenção de pessoas (ILLEGEMS; VERBEKE; S'JEGERS, 2001) e aumento de produtividade (ANSONG; BOATENG, 2018), enquanto há dificuldade de desenvolvimento de atividades em equipe 
(ILLEGEMS; VERBEKE, 2004) e controle de performance (TUNG; TURBAN, 1996). Para a sociedade, é identificado benefícios à medida que há a redução na emissão de poluentes e redução de uso do papel devido ao teletrabalho (HAZAN; MORATO, 2018).

Por fim, pode-se identificar lacunas de pesquisa para estudos futuros. Percebe-se que ainda há poucos estudos específicos no serviço público, sendo de grande importância a construção teórica para esse tipo de organização, principalmente no Brasil, onde identifica-se cada vez mais instituições públicas fazendo uso dessa modalidade laboral. Identifica-se que há poucos estudos de cunho longitudinal (HUNTON; NORMAN, 2010), isto é, que verificam o teletrabalho ao longo do tempo. Visto que é uma modalidade recente (DA COSTA, 2007), torna-se interessante verificar o seu impacto ao longo dos anos. Ademais, visto que o principal foco de estudo dos artigos foi o impacto que o teletrabalho traz, considera-se importante a verificação de formas e métodos em manter os impactos positivos e diminuir os impactos negativos no decorrer do tempo. Por último, verifica-se que poucos estudos fazem análise combinando os diversos atores envolvidos nessa nova forma laboral, principalmente em relação as equipes de trabalho (COENEN; KOK, 2014).

$\mathrm{O}$ artigo contribui ao apresentar o estado da arte da literatura de teletrabalho e propor lacunas teóricas para futuras pesquisas. Em relação à prática, o artigo contribui ao apresentar fatores que induzem ou dificultam a implementação do teletrabalho, assim como impactos positivos e negativos que podem ser gerados pelo uso dessa modalidade laboral nas organizações. O presente artigo, ainda, limita-se ao portifólio selecionado e ao foco de estudo dos artigos, não avaliando outras variáveis dos artigos selecionados.

\section{AGRADECIMENTO}

Agradecemos, à Coordenação de Aperfeiçoamento de Pessoal de Nível Superior (CAPES) e ao Programa de Monitoria de Pós-Graduação (PROMOP) da Universidade do Estado de Santa Catarina (UDESC), pelo auxílio financeiro recebido em forma de bolsas de estudo, respectivamente, em níveis de doutorado e de mestrado. Também agradecemos à Fundação de Amparo à Pesquisa e Inovação do Estado de Santa Catarina (FAPESC) pelo suporte ao grupo de pesquisa. 


\section{REFERÊNCIAS}

ABDULLAH, H.; ISMAIL, N. Quality of work and life balance in teleworking. International Business Management, v. 6, n. 2, p. 119-130, 2012.

ADERALDO, I. L.; ADERALDO, C. V. L.; LIMA, A. C. Aspectos críticos do teletrabalho em uma companhia multinacional. Cadernos EBAPE. BR, v. 15, n. 3, p. 511-533, 2017.

AGUILERA, A. et al. Home-based telework in France: Characteristics, barriers and perspectives. Transportation Research Part A: Policy and Practice, v. 92, p. 1-11, 2016.

ANSONG, E.; BOATENG, R. Organisational adoption of telecommuting: Evidence from a developing country. The Electronic Journal of Information Systems in Developing Countries, v. 84, n. 1, p. e12008, 2018.

ARAÚJO, C. A. Bibliometria; evolução histórica e questões atuais. Em Questão, v. 12, n. 1, p. 11-32, jan./jun., 2006.

BAILEY, D. E.; KURLAND, N. B. A review of telework research: Findings, new directions, and lessons for the study of modern work. Journal of Organizational Behavior: The International Journal of Industrial, Occupational and Organizational Psychology and Behavior, v. 23 , n. 4 , p. 383-400, 2002.

BAYRAK, T. IT support services for telecommuting workforce. Telematics and informatics, v. 29, n. 3, p. 286-293, 2012.

BÉLANGER, F. Workers' propensity to telecommute: An empirical study. Information \& Management, v. 35, n. 3, p. 139-153, 1999.

BÉLANGER, F.; WATSON-MANHEIM, M. B.; SWAN, B. R. A multi-level socio-technical systems telecommuting framework. Behaviour \& Information Technology, v. 32, n. 12, p. 1257-1279, 2013.

BOTELHO, L. L. R.; CUNHA, C. C. D. A.; MACEDO, M. O método da revisão integrativa nos estudos organizacionais. Gestão e Soc., v. 5 n. 11, p. 121-36, 2011.

CAMPBELL, J.; HEALES, J. Factor Structure of Individual Consequences for Teleworking Professionals. Australasian Journal of Information Systems, v. 20, 2016.

COENEN, M.; KOK, R. A. W. Workplace flexibility and new product development performance: The role of telework and flexible work schedules. European Management Journal, v. 32, n. 4, p. 564-576, 2014.

COLLINS, A. M.; HISLOP, D.; CARTWRIGHT, S. Social support in the workplace between teleworkers, office-based colleagues and supervisors. New Technology, Work and Employment, v. 31, n. 2, p. 161-175, 2016. 
CONTRERAS, O. E.; ROZO ROJAS, I. Teleworking and business sustainability. A reflection from the Human Resource Management in Colombia. Suma de negocios, v. 6, n. 13, p. 74-83, 2015.

COOKE, G.; CHOWHAN, J.; COOPER, T. Dialing it in: A Missed Opportunity Regarding the Strategic Use of Telework?. Relations industrielles/Industrial Relations, v. 69, n. 3, p. 550574, 2014.

CORDEIRO, A. M., OLIVEIRA, G. M. D., RENTERÍA, J. M., GUIMARÃES, C. A. Revisão sistemática: uma revisão narrativa. Rev. Col. Bras. Cir, v. 34, n. 6, p. 428-431, 2007.

DA COSTA, I. S. A. Teletrabalho: subjugação e construção de subjetividades. Revista de Administração Pública, v. 41, n. 1, p. 105-124, 2007.

DA SILVA, J. A. Flexibility and telework: a study about scientific production analysis. Perspectivas em Ciência da Informação, v. 19, n. 2, p. 159-173, 2014.

DUTCHER, E. G. The effects of telecommuting on productivity: An experimental examination. The role of dull and creative tasks. Journal of Economic Behavior \& Organization, v. 84, n. 1, p. 355-363, 2012.

DUXBURY, L.; NEUFELD, D. An empirical evaluation of the impacts of telecommuting on intra-organizational communication. Journal of Engineering and Technology Management, v. 16, n. 1, p. 1-28, 1999.

FELDMAN, D. C.; GAINEY, T. W. Patterns of telecommuting and their consequences: Framing the research agenda. Human Resource Management Review, v. 7, n. 4, p. 369-388, 1997.

FROLICK, M. N.; WILKES, R. B.; URWILER, R. Telecommuting as a workplace alternative: an identification of significant factors in American firms' determination of work-at-home policies. The Journal of Strategic Information Systems, v. 2, n. 3, p. 206-220, 1993.

GOLDEN, T. D. Avoiding depletion in virtual work: Telework and the intervening impact of work exhaustion on commitment and turnover intentions. Journal of vocational behavior, $\mathrm{v}$. 69, n. 1, p. 176-187, 2006.

GROEN, B. A. C. et al. Managing flexible work arrangements: Teleworking and output controls. European Management Journal, v. 36, n. 6, p. 727-735, 2018.

HADDON, L.; BRYNIN, M. The character of telework and the characteristics of teleworkers. New Technology, Work and Employment, v. 20, n. 1, p. 34-46, 2005.

HAU, F.; TODESCAT, M. Teleworking in the perception of teleworkers and their managers: advantages and disadvantages in a case study. NAVUS-REVISTA DE GESTAO E TECNOLOGIA, v. 8, n. 3, p. 37-52, 2018.

HAZAN, B. F.; MORATO, A. D. P. Teleworking in Brazilian law: grounds, perspectives and changes promoted by labor reform. Lex Humana, v. 10, n. 1, p. 1-24, 2018. 
HIDALGO, A.; ALBORS, J. Innovation management techniques and tools: a review from theory and practice. R\&D Management, v. 38, n. 2, p. 113-127, 2008.

HILL, E. J.; FERRIS, M.; MÄRTINSON, V. Does it matter where you work? A comparison of how three work venues (traditional office, virtual office, and home office) influence aspects of work and personal/family life. Journal of Vocational Behavior, v. 63, n. 2, p. 220-241, 2003.

HUNTON, J. E.; NORMAN, C. S. The impact of alternative telework arrangements on organizational commitment: insights from a longitudinal field experiment (retracted). Journal of Information Systems, v. 24, n. 1, p. 67-90, 2010.

ILLEGEMS, V.; VERBEKE, A. Telework: what does it mean for management?. Long Range Planning, v. 37, n. 4, p. 319-334, 2004.

ILLEGEMS, V.; VERBEKE, A.; S'JEGERS, R. The organizational context of teleworking implementation. Technological forecasting and social change, v. 68, n. 3, p. 275-291, 2001.

KATZ, A. I. The management, control, and evaluation of a telecommuting project: A case study. Information \& Management, v. 13, n. 4, p. 179-190, 1987.

KOSSEK, E. E.; LAUTSCH, B. A.; EATON, S. C. Telecommuting, control, and boundary management: Correlates of policy use and practice, job control, and work-family effectiveness. Journal of Vocational Behavior, v. 68, n. 2, p. 347-367, 2006.

KUGELMASS, J. Teletrabalho: novas oportunidades para o trabalho flexível. São Paulo: Atlas, 1996.

KURLAND, N. B.; COOPER, C. D. Manager control and employee isolation in telecommuting environments. The Journal of High Technology Management Research, v. 13, n. 1, p. 107126, 2002.

LEE, H.; SHIN, B.; HIGA, K. Telework vs. central work: A comparative view of knowledge accessibility. Decision Support Systems, v. 43, n. 3, p. 687-700, 2007.

MARUYAMA, T.; HOPKINSON, P. G.; JAMES, P. W. A multivariate analysis of work-life balance outcomes from a large-scale telework programme. New Technology, Work and Employment, v. 24, n. 1, p. 76-88, 2009.

MOKHTARIAN, P. L.; SALOMON, I. Modeling the desire to telecommute: The importance of attitudinal factors in behavioral models. Transportation Research Part A: Policy and Practice, v. 31, n. 1, p. 35-50, 1997.

NEIROTTI, P.; PAOLUCCI, E.; RAGUSEO, E. Telework configurations and labour productivity: some stylized facts. International Journal of Engineering Business Management, v. 4, n. Godište 2012, p. 4-5, 2012.

NILLES, J. M. Traffic reduction by telecommuting: A status review and selected bibliography. Transportation Research Part A: General, v. 22, n. 4, p. 301-317, 1988. 
PÉREZ, M. P.; SÁNCHEZ, A. M.; CARNICER, M. P. L. Benefits and barriers of telework: perception differences of human resources managers according to company's operations strategy. Technovation, v. 22, n. 12, p. 775-783, 2002.

PETERS, P.; TIJDENS, K. G.; WETZELS, C. Employees' opportunities, preferences, and practices in telecommuting adoption. Information \& Management, v. 41, n. 4, p. 469-482, 2004.

ROCHA, C. T. M.; AMADOR, F. S. O teletrabalho: conceituação e questões para análise. Cadernos EBAPE. BR, v. 16, n. 1, p. 152-162, 2018.

ROSENFIELD, C. L.; DE ALVES, D. A. Autonomy and information work: telework. Dados, v. 54, n. 1, p. 207-233, 2011.

SOLÍS, M. Moderators of telework effects on the work-family conflict and on worker performance. European Journal of Management and Business Economics, v. 26, n. 1, p. 21 34, 2017.

SULLIVAN, C.; LEWIS, S. Home-based telework, gender, and the synchronization of work and family: perspectives of teleworkers and their co-residents. Gender, Work \& Organization, v. 8, n. 2, p. 123-145, 2001.

TEO, T. S. H.; LIM, V. K. G.; WAI, S. H. An empirical study of attitudes towards teleworking among information technology (IT) personnel. International journal of information management, v. 18, n. 5, p. 329-343, 1998.

TREMBLAY, D. Organização e satisfação no contexto do teletrabalho. Revista de Administração de Empresas, v. 42, n. 3, p. 54-65, 2002.

TREMBLAY, D.; THOMSIN, L. Telework and mobile working: analysis of its benefits and drawbacks. International Journal of Work Innovation, v. 1, n. 1, p. 100-113, 2012.

TUNG, L. L.; TURBAN, E. Information technology as an enabler of telecommuting. International Journal of Information Management, v. 16, n. 2, p. 103-117, 1996.

VAN DEN BROEK, D.; KEATING, E. Rights to a process for the masses or select privileges for the few? Telework policy and labour market inequality in Australia. Policy Studies, v. 32, n. 1, p. 21-33, 2011.

VAN SELL, M.; JACOBS, S. M. Telecommuting and quality of life: a review of the literature and a model for research. Telematics and Informatics, v. 11, n. 2, p. 81-95, 1994.

VARGAS, A. V.; OSMA, J. I. P. Proposal for implementing a telecommuting model/Propuesta de implementación de un modelo de teletrabajo. RISTI (Revista Ibérica de Sistemas e Tecnologias de Informação), n. 12, p. 17-32, 2013.

VITTERS $\varnothing$, J. et al. Impacts of home-based telework on quality of life for employees and their partners. Quantitative and qualitative results from a European survey. Journal of Happiness Studies, v. 4, n. 2, p. 201-233, 2003. 
WOJCAK, E. et al. How to achieve sustainable efficiency with teleworkers: Leadership model in telework. Procedia-Social and Behavioral Sciences, v. 229, p. 33-41, 2016.

WORKMAN, M.; KAHNWEILER, W.; BOMMER, W. The effects of cognitive style and media richness on commitment to telework and virtual teams. Journal of Vocational Behavior, v. 63, n. 2, p. 199-219, 2003. 